\title{
Electronic Pedal Shifting Assembly using Bi-Directional Solenoid
}

\author{
Omkar Taru, Ruturaj Mane \\ Third Year Mechanical Department \\ JSPM's Rajarshi Shahu College of Engineering \\ Pune, India.
}

\author{
Shubham Garde, Pravin Jadhav \\ Final Year Mechanical Department \\ JSPM's Rajarshi Shahu College of Engineering \\ Pune, India.
}

\begin{abstract}
Linear actuator is the most effective method for racing cars to reduce the shifting time. The paper elaborates a practical approached of designing and implementation of solenoid gear shifting. A solenoid has been widely used among electromagnetic actuators, because of its simple structure. It can be actuated in one or both the direction. Magnitude of the electromagnetic force can be easily controlled by changing the input current applied to the solenoid. Variation in input current will vary solenoid force. We designed and fabricate bidirectional solenoid. It has many advantages for the gear shifting in automobiles. It is compact in design and it improves driving performance of overall car. This solenoid uses a long loop of wire wrapped around a metallic core (plunger), and it produces a magnetic field to generate the linear motion of the plunger when an electric current is passed through the wire coil.
\end{abstract}

Keywords- Electronic Solenoid, Pedal Shifting, 3D Printed Pedal.

\section{INTRODUCTION}

Solenoid works on principals of Hydraulic, Pneumatics and Electronic. Linear solenoids can be either unidirectional (push or pull) or bi-directional (push and pull) and they often have a two spring return to bring the plunger back to the home position.

Manual gear shifting or manual transmissions come in two basic types: simple unsynchronized systems, where gears are spinning freely. Whereas the other one is the synchronized systems, in which all gears are always in mesh but only one of these meshed pairs of gears is locked to the shaft on which it is mounted at any one time, the others being allowed to rotate freely; thus greatly reducing the skill required to shift gears.

The electronic shift system is designed for the Formula SAE car so that the driver would be able to actuate a shift without removing his or her hand from the steering wheel, increasing control at every point in the race. As well, the amount of energy required by the driver to actuate the shift is minimized to reduce the fatigue of the driver during a race as compared to the current push-pull lever system being used. This leads to faster shift times, better performance overall and better driver control increasing the safety of the vehicle.

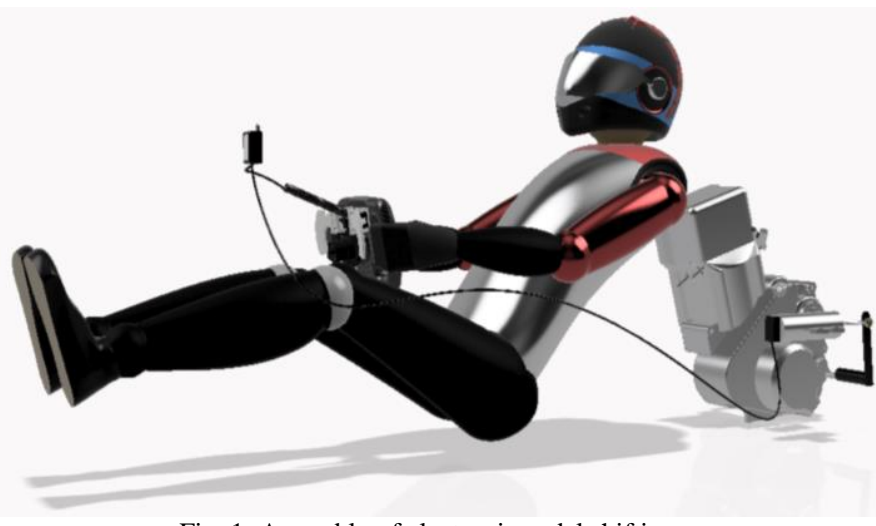

Fig. 1: Assembly of electronic pedal shifting

\section{PROJECT OVERVIEW}

Lever actuated mechanism for gear shifting was user in 2019 car. Shifter cable used in commercial vehicles was used as a link between shifter lever and engine gear arm. This mechanism is not that effective as need in race cars as it affects increase in time to shift. The driver has to move his hand from steering wheel to shift the gear. This process has the following drawbacks:

1. If shifting in the middle of a corner, the driver will only have one hand on the steering wheel, reducing the amount of control they have of the vehicle.

2. The time required to change gears is currently on the order of seconds.

\section{Solution to overcome this drawbacks:}

The solution to these drawbacks is to implement an electronic shifting mechanism with steering- wheel -mounted paddles to control the up- and down-shifting. This allows the driver to keep both hands on the steering wheel and may reduce the amount of time required for shifting by an order of magnitude. The result of these modifications will be a safer, quicker vehicle. 


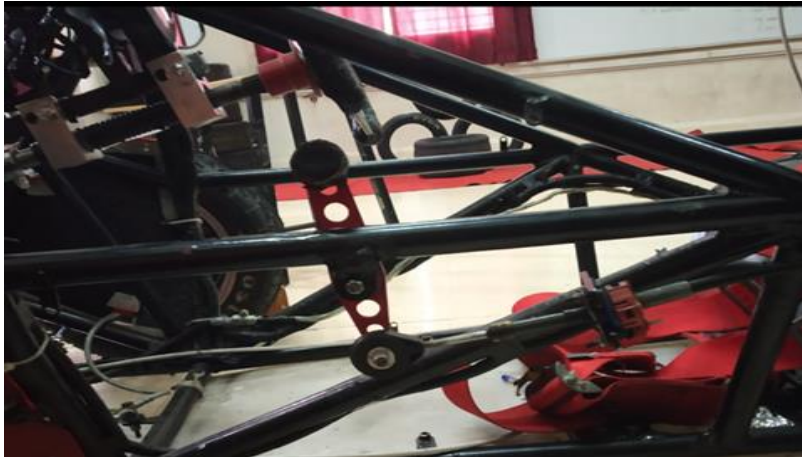

Fig 2: Lever actuated gear shifting mechanism.

\section{PROJECT GOALS}

There were 2 primary goals for the development of an Electronic Shifter. These were decided considering onset of project and to focus on our design objectives:

- $\quad$ Practical Considerations

The new shifting device that is developed will play a vital role in the operation of the next car the SAE team builds. Therefore, the design must be driven by the practical considerations that the team will face when building and using the system. This includes the cost, and availability of replacement parts.

- Maintain the reliability of the mechanical shifter. The current shifter is a simple mechanical device with a direct linkage to the transmission at the rear of the car. One of the fundament challenges for the SAE team is system reliability, this cannot be sacrificed, and all new developments need to be tested to ensure they are more reliable than the previous design.

\section{DESIGN OF SOLENOID}

\section{Pre-Design Considerations}

\subsection{Linear Actuator Selection and Testing:}

The linear actuator is a major component of this project. It connects directly to the transmission shift mechanism and functions to replace the force generated by a human operator moving a mechanical lever. In light of this, a significant amount of testing and research was directed towards choosing an appropriate linear actuator. Finally we build custom made electric solenoid for our project as shown in fig.

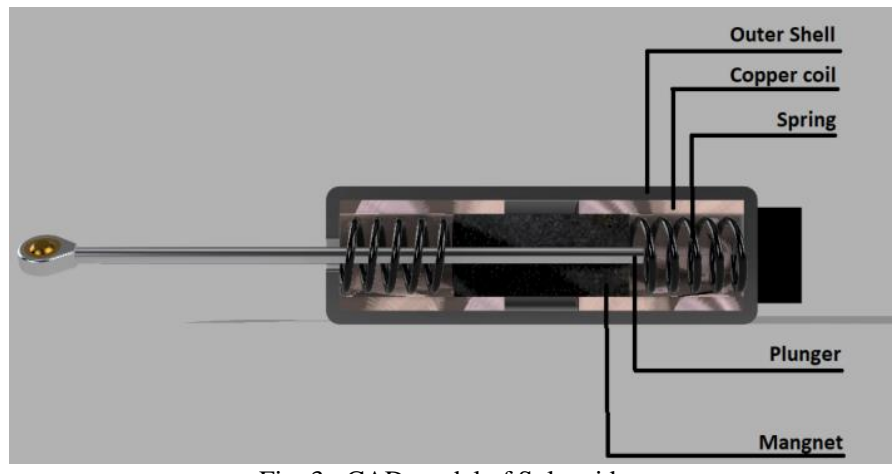

Fig. 3 : CAD model of Solenoid.

\subsection{Force Measurement:}

In order to help us with selection of a linear actuator, we made a series of force measurements. Both Shifting Up and Down Shift Forces were measured with the help spring balance. As shown in fig. we use spring balance for measuring engine transmission lever forces. We simply attached one end of spring balance to engine shifting lever that we made using mild steel and KTM stock lever. We simply pull spring balance at different shifts during engine running conditions and recorded that data that we got on spring balance pointer display. KTM 390 engine has 6 speed transmission gearbox so we take readings for upshift from 16 and for downshift 6-1. The recorded data is plot in table as shown in figures.

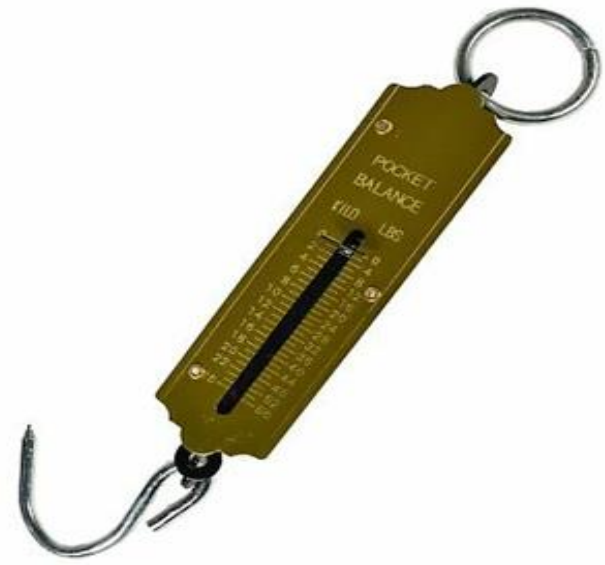

Fig 4 : Spring Balance

\begin{tabular}{|c|c|c|}
\hline From & To & Shifting Up Force $(\mathbf{k g})$ \\
\hline 1 & 2 & 6 \\
\hline 2 & 3 & 5 \\
\hline 3 & 4 & 6 \\
\hline 4 & 5 & 5 \\
\hline 5 & 6 & 4.5 \\
\hline
\end{tabular}

Table 1 : Force table for shifting up

\begin{tabular}{|c|c|c|}
\hline From & To & Shifting Down Force $(\mathbf{K g})$ \\
\hline 6 & 5 & 5.5 \\
\hline 5 & 4 & 5 \\
\hline 4 & 3 & 4.5 \\
\hline 3 & 2 & 5 \\
\hline 2 & 1 & 5.5 \\
\hline
\end{tabular}

Table 2 : Force table for shifting down

As seen, the maximum force measured was 5.5. Since we need a force that will always be guaranteed to shift the transmission so $8 \mathrm{~kg}$. was selected. So we take $8 \mathrm{~kg}$ force as a given design solenoid accordingly.

\section{Actual Design}

In general, the magnetic field of the solenoid is related to the current, coil turns and the iron core inside solenoid. So that, in the process of the solenoid design, we should focus on the winding distribution and iron core selection, and use the size of current to control the magnetic field.

As for the electromagnetic force of the solenoid, which is decided by the current and coil turns. The bigger current, the bigger electromagnetic force; the more coil turns, the bigger electromagnetic force. 


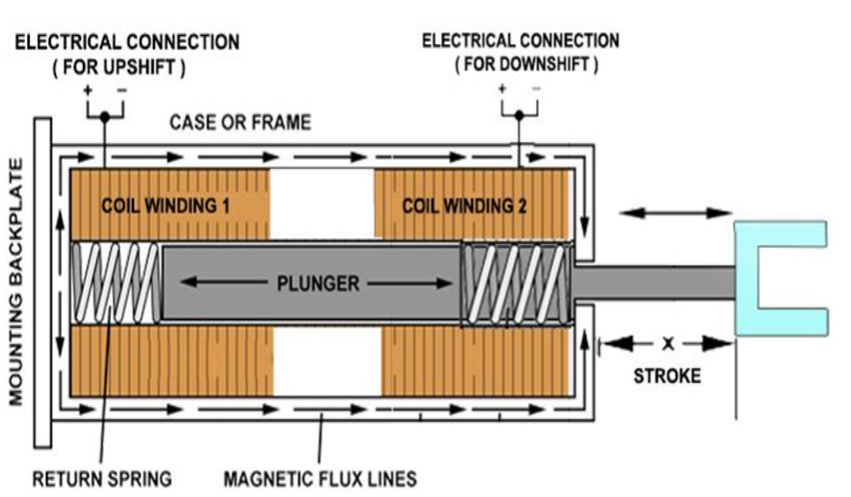

Fig. 5: Cross section view of solenoid

\subsection{Calculations}

\subsubsection{Stroke Length calculations:}

By geometry,

Angle of rotation $=20.5^{\circ}$

Length of arm $=80 \mathrm{~mm}$

Required stroke length $=80 \times \tan 30$

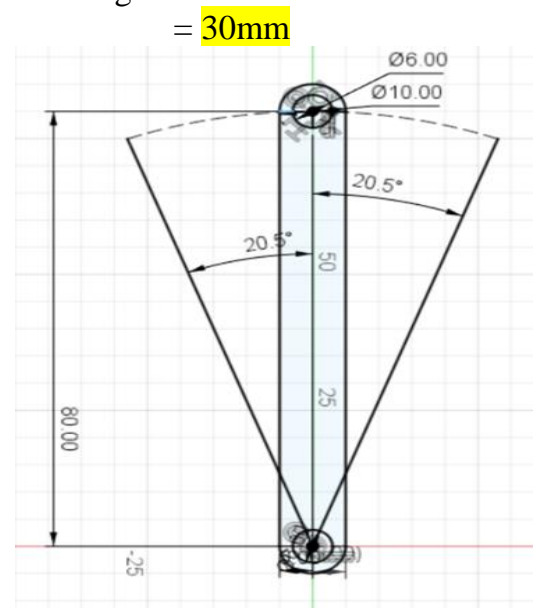

Fig. 6: Geometry of shift arm

\subsubsection{Torque Required:}

Maximum Practical force measured by spring balance at shifter $\operatorname{arm} \mathrm{T}_{\max }=6 \mathrm{Kg}$.

By considering spring losses and calibration error taking FOS of 1.33 .

So, targeted $\mathrm{T}_{\max }=8 \mathrm{KG}$

$$
=78.4 \mathrm{~N}
$$

Force at shifter $=980 \mathrm{Nm}$

\subsubsection{Magnetic Field:}

To find magnetic field in Terlor required to achieve maximum torque.

Force developed by electromagnet

$\mathrm{F}=\mathrm{B}^{2} * \mathrm{~A} / 2 \mathrm{u}$

Where,

$\mathrm{B}=$ magnetic field in Terlor

$\mathrm{u}=$ permeability of space $\left(4^{*} \pi^{*} 10^{-7}\right)$

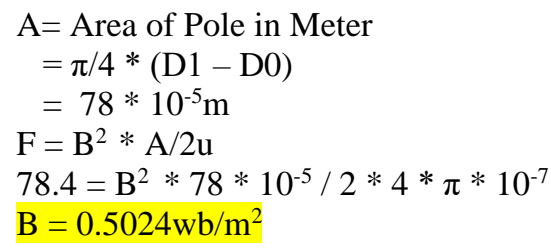

\subsubsection{Number of Coils:}

Calculation for number of turns of copper wire requires for solenoid for normal operating condition.

Magnetic field equation

$\mathrm{B}=\mathrm{u} * \mathrm{~N} * 1 / \mathrm{L}$

$\mathrm{B}=$ magnetic field in Terlor

$\mathrm{N}=$ number of turns of copper wire

$\mathrm{I}=$ Current supplied in amp

(12 amp =measured at current input of solenoid)

$\mathrm{L}=$ Length of plunger

$\mathrm{u}=$ permeability of space $\left(4 * \pi * 10^{-7}\right)$

$0.502=4 * \pi * 10^{-7} * \mathrm{~N} * 12 /\left(60 * 10^{-3}\right)$

$\mathrm{N}=2000$ (Number of Coils)

2.1.5 Power required for operating solenoids:

Required voltage $=12 \mathrm{v}$

Required ampere $=5 \mathrm{amp}$

Power required for one solenoid $=\mathrm{V} * \mathrm{I}$

$$
=12 * 12
$$

Power $=144$ watt

\subsubsection{Spring calculations}

Spring material - Steel alloy

Material properties:-

1) Youngs modulus $=190 \mathrm{GPA}$

2) Poisson ratio $=0.3$

3) Density of material $=7550 \mathrm{~kg} / \mathrm{m}^{3}$

\begin{tabular}{|c|c|c|}
\hline Diameter of spring wire, $d$ : & 3 & $\mathrm{~mm} \sim$ \\
\hline Outer diameter of spring, $D_{\text {outer }}$ & 12 & $\mathrm{~mm} \sim$ \\
\hline Free length of spring, $L_{\text {iree: }}$ & 40 & $\mathrm{~mm} \sim$ \\
\hline Number of active coils, $n_{\mathrm{a}}$ : & 8 & \\
\hline Youngs modulus of material. $E$ : & 190 & GPa $~-$ \\
\hline Poisson ratio of material, $\underline{\nu}$ : & 0,3 & \\
\hline Density of material, $\mathrm{\rho}$ : & 7750 & $\mathrm{~kg} / \mathrm{m}^{\wedge} 3 \vee$ \\
\hline
\end{tabular}

Inputs

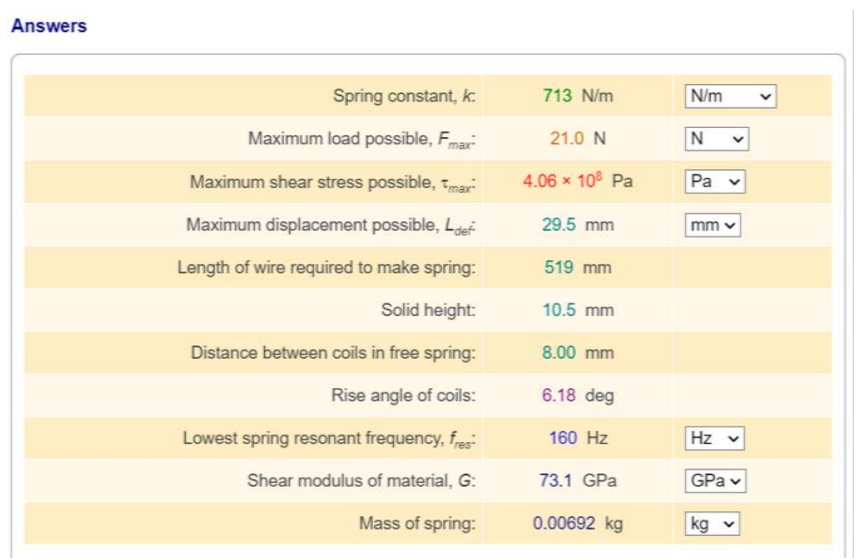




\section{Manufacturing of Solenoid}

SS304 was used as an outer shell. As SS304 has required Tensile strength and Heat conductivity. Stainless Steel Tubes are available in market for various diameters and thickness. The outer case was designed to sustain $100 \mathrm{~N}$ force considering FOS of 1.26. And SS has the same sustainable force at lower weight.

\subsection{Assembly of Solenoid:}

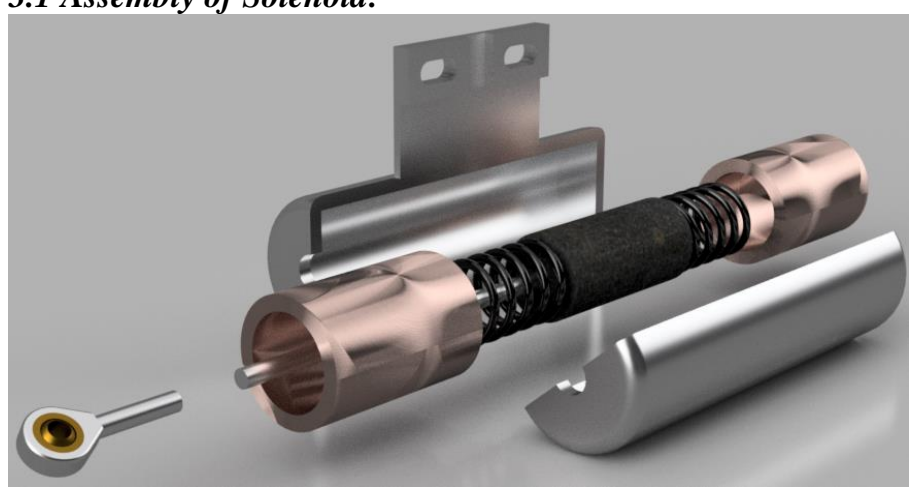

Fig. 7 : Exploded view of components in solenoid.

Step:1- Welding mount on outer casing and insulating case from inside.

Step:2- Press fitting Copper windings inside the case.

Step:3- Press fitting spring.

Step:4- Plunger assembly.

Step:5- Press fitting core and spring.

Step:6- Connections and wiring.

Step:7- Screwing ball joint at rod end.

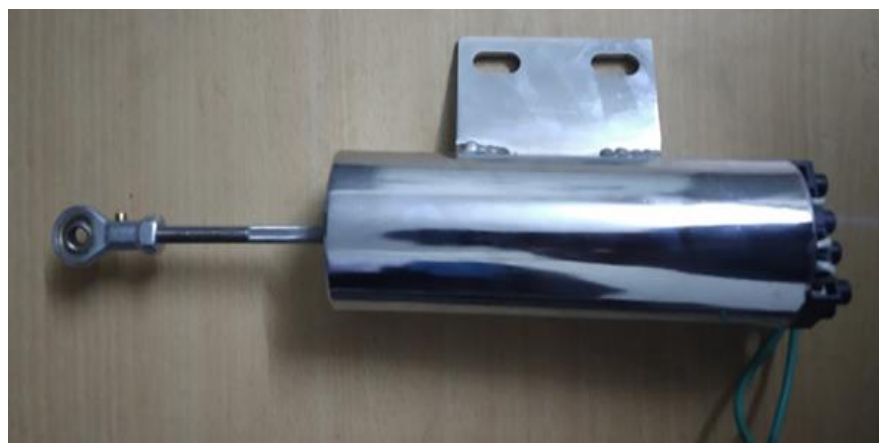

Fig. 8: Manufactured Product

\section{Design of Mount}

Cantilever mount was designed hold the solenoid rigidly. And to maintain proper pivot ratio between shifter shaft of engine and solenoid. It is designed to sustain the its own weight and maximum torque.

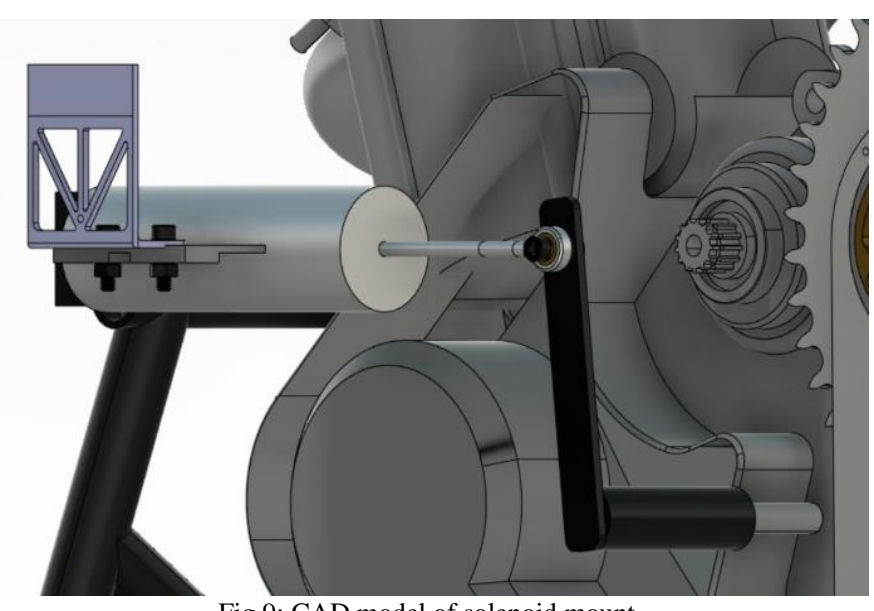

Fig 9: CAD model of solenoid mount

\subsection{Force Distribution:}

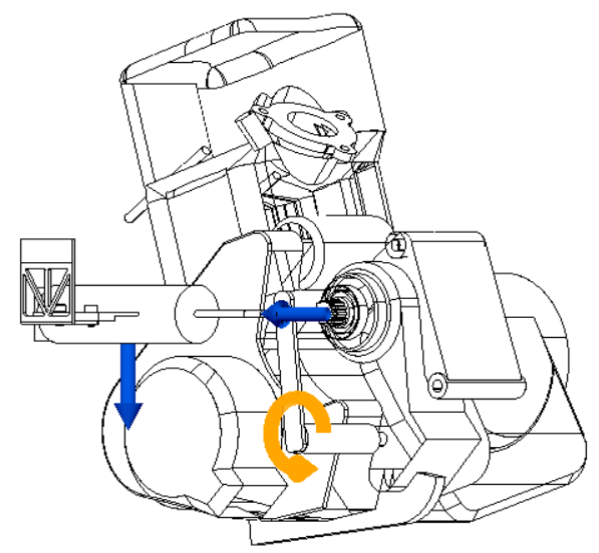

Fig 10: Different forces acting on solenoid mount

\subsection{Analysis of Mount:}

CAD file for analyzing the behavior of mount against forces acting on it using ANSYS software. So we take forces acting on this mount in longitudinal direction as . We took actuator maximum working force that's $8 \mathrm{~kg}$ as a reference while giving inputs to software. We gave the inputs to software like type of material, forces acting on mount longitudinal direction from the actuator and took self-weight of actuator that's $1.8 \mathrm{~kg}$ gravity side. As shown in image the mount was optimized by using iterative method. After reaching at the final optimization stage, then the design was freeze and then moved further manufacturing stage.

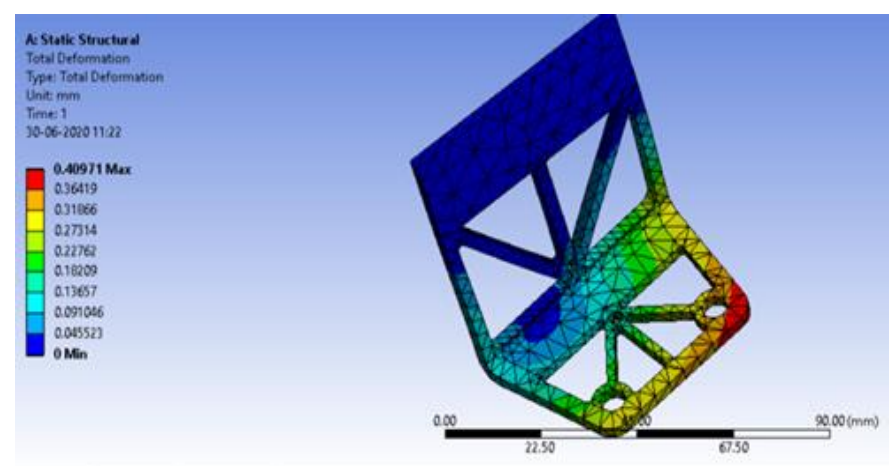

Fig. 11: Total Deformation 


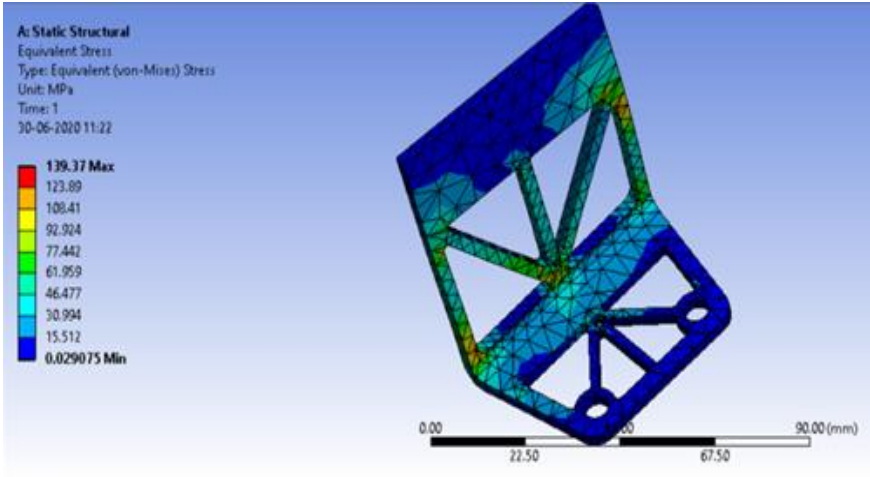

Fig. 12: Equivalent Stress

\subsection{Design and Manufacturing of Mount:}

Mild steel was selected for mount. There advantages of mild steel are low cost and easy weld to steel member of chassis using TIG welding. Firstly we generate DWG file using designing software. For manufacturing of mount high accuracy Laser cut machine was used. But mount manufactured was in 2D form. For $90^{\circ}$ bend Hydraulic bending was used.

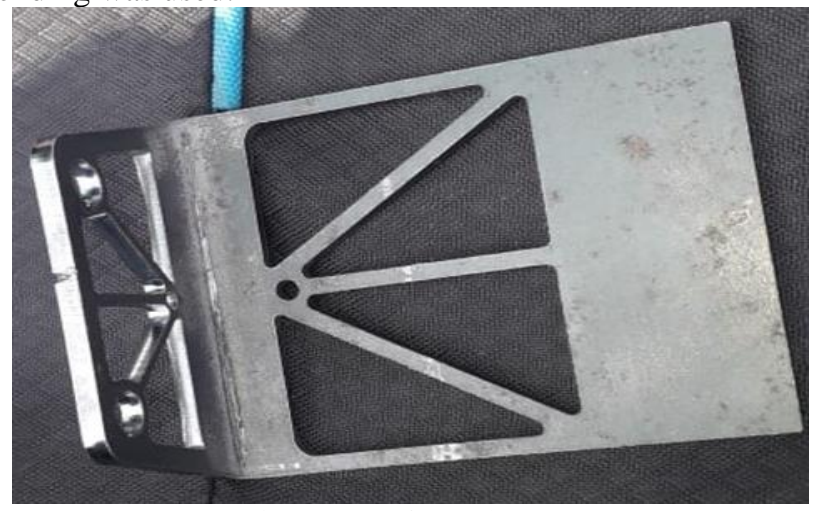

Fig. 13: Manufactured Mount

\section{Steps for Design and manufacturing of mount.}

1. CAD modelling of mount in Autodesk fusion 360 .

2. Analysis of Mount.

3. Generate DWG file using design software.

4. Laser cutting of mild steel mount.

5. Use Bending machine for bending mount at 90deg.

6. Welding mount to the chassis.

\section{Electronic Connections}

\subsection{Circuit Diagram:}

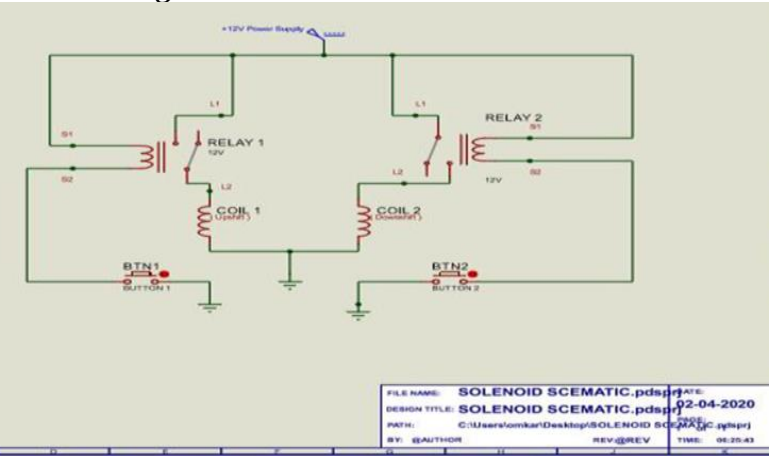

Fig. 14: Schematic representation of electric circuit.

\subsection{Switch Selection:}

OFF-ON-OFF switch were selected. Because a specific amount of current should be passed through the circuit within less then $1 \mathrm{sec}$. Compact switches were selected due the less area available for the assembly. The switches were attached to the backside of the steering wheel which must fit in shifter mount.
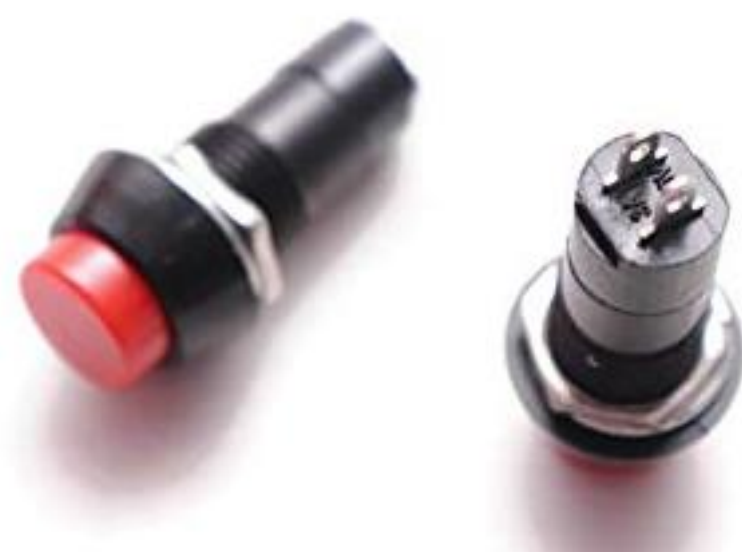

Fig. 15: OFF-ON-OFF Switch to actuate Solenoid

\subsection{Relay Selection:}

Relay is used as a switching element when operator or driver press the paddle then small amount of voltage is supplied to the terminals of relay. Relay connects high voltage as a result current flows through a first circuit and gear will be shifted accordingly. We used commercial dual DPDT (Double pole double throw) type relay for the application. DPDT relay was used because it can control two separate circuits, but are always switched together by a single actuator.

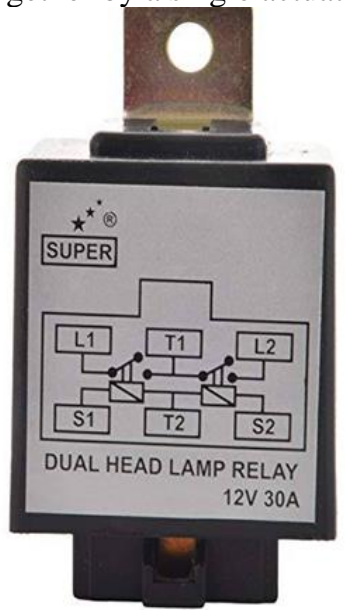

Fig. 16: Dual coil relay

\subsection{Quick release removal connector:}

According to FSAE rules, in case of emergency for egress steering wheel should be quickly removable by driver. Which implies that any electronic equipment mounted on the steering wheel must be connected via detachable connector. Detachable connector involves opening of circuit when the steering wheel is removed from the steering shaft. So detachable connectors were used for quick ON-OFF connection. Connector harness must be compatible to the motion of the steering wheel. So spiral cables were used. 


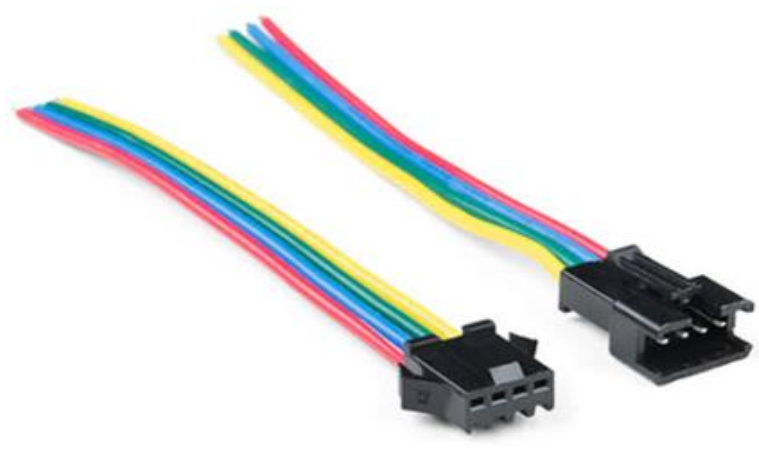

Fig. 17: Removable Connectors

\section{Pedal Shifting Assembly}

Drivers with electronically actuated shifting system, actuate switches manually to change gears by means of solenoid. In this system driver electrically shift gear, rather than traditional gear-shift lever on a manual transmission. It is comparatively easier for drivers to maintain control at extremely high racing speeds or in demanding situations that required both hands on the steering wheel.

Decision of Choosing Paddle shifters over buttons was as per driver's ease, pedal shifters let mechanically actuate off-onoff switch which is press-fitted in mount of shifter. Two different pedals used in order to upshift and downshift, right pedal is used for upshifting and left for downshifting

Advantages of paddle shifting in dynamic conditions are as follows

\section{1)Downshifting}

When driver need to rapidly slow down at sharp turn at a corner, uses the left paddle to lower your gear down. As it provides extra torque to maneuver quickly.

\section{2) Upshifting}

Reducing the amount of torque that is sent to your vehicle's drive wheels. This results to prevent wheel spin in order to maintain traction on the road. Upshifting with actuator is very effective in dynamic events.

\subsection{Design of pedal shifter:}

To get exact position and actuation ease according to will of both drivers so it was decided to use rapid prototyping method. That way we can make basic skeleton which is flexible and once it is fixed, we can construct MDF prototype. Shifter assembly with switch was independent of steering so it can have shiftability at time of mounting on steering wheel.

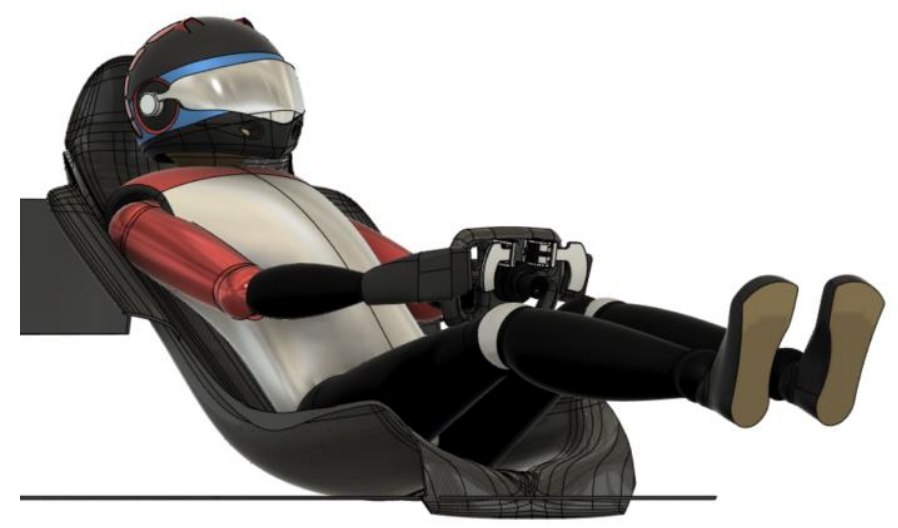

Fig. 18: Ergonomics of drivers position

\subsubsection{Prototype iteration method:}

As per reference of skeleton, firstly we made MDF paddle mounts and attached it to cardboard of steering wheel draft to check the ergonomics of the driver for shifting gears. According to driver inputs we fixed our constraints and finalized the paddle design which is suitable for our steering wheel.

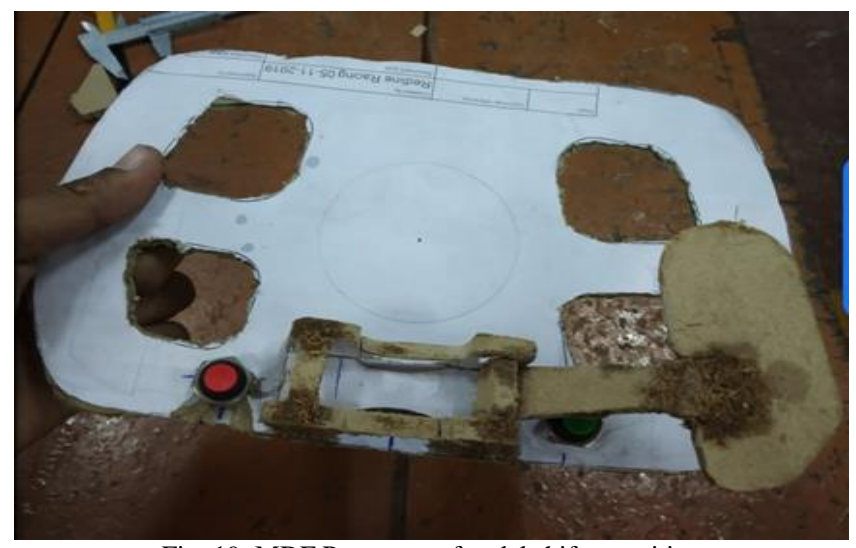

Fig. 19: MDF Prototype of pedal shifter position

\subsubsection{D modelling:}

Cad design of paddle shifters was made using Autodesk fusion 360 software. With help of optimizing tools possible light-weight shifter were designed.
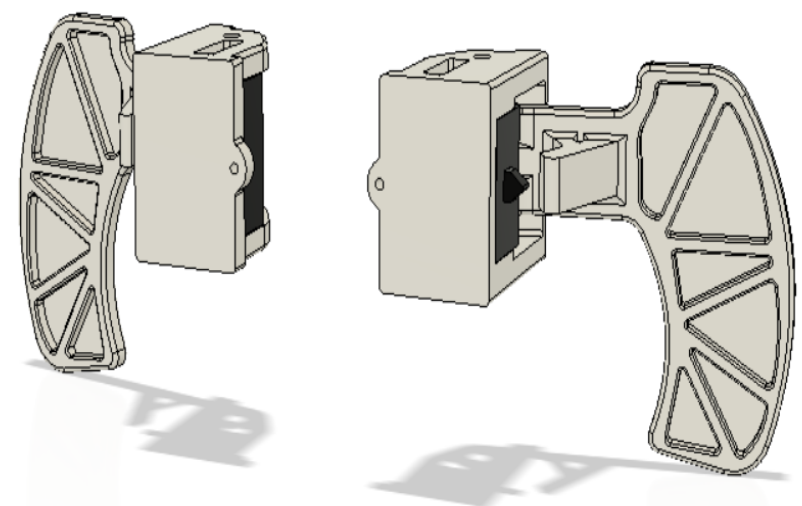

Fig. 20: CAD assembly of pedal shifter 


\subsubsection{Manufacturing method:}

We manufactured paddles using 3D printing technology as we need high accuracy for proper force distribution and perfectly press fit switches. ABS was chosen as a material for paddles because of high strength at lower weights.

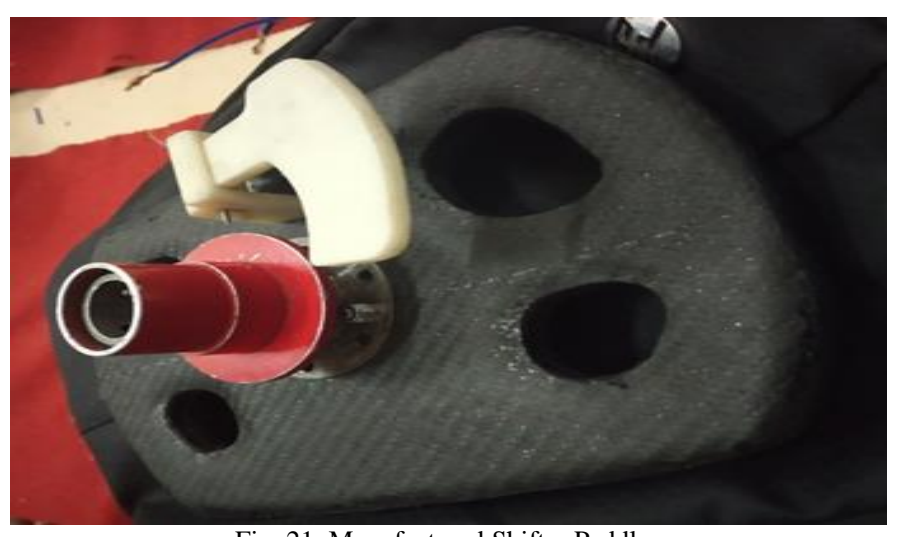

Fig. 21: Manufactured Shifter Paddle

\section{CONCLUSION}

Electronic Paddle Shifter System was a project that greatly improved our understanding of concepts involved in the engineering process. Throughout the project we encountered many obstacles and problems in the researching, designing, prototyping, and testing stages.

\section{ACKNOWLEDGMENT}

The authors would like to thank Team Redline Racing for allowing and helping them to implement and test this setup solenoid shifter.

\section{REFERENCES}

[1] "Solenoid Operated Gear Shifting Mechanism for Two Wheeler." Journal of Recent Trends in Mechanics. DOI: 10.13140/RG.2.2.29857.04966.

[2] (https://www.efunda.com/DesignStandards/springs/calc_comp_desig ner.cfm) Calculation spring.

\section{AUTHORS}

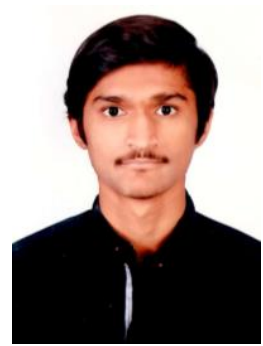

Shubham R. Garde

The Author is currently in the final year of bachelors of Mechanical Engineering from the JSPM'S RSCOE Pune, India. Author is passionate about Automobiles, and interested in Designing and Manufacturing. Author is Formula Student Driver at Team Redline Racing.

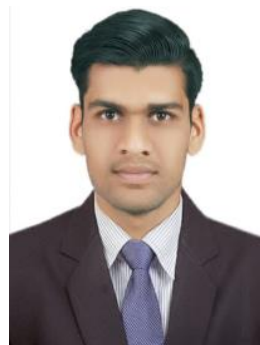

\section{Pravin S. Jadhav}

The Author is currently in the Final year of bachelors of Mechanical Engineering from the JSPM'S RSCOE Pune, India. Author is interested in Product design using modelling software's. Author is Design Head at Team Redline Racing.

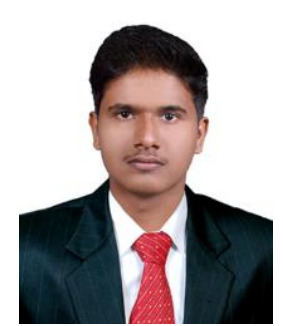

Ruturaj R. Mane

The Author is currently in the third year of bachelors of Mechanical Engineering from the JSPM'S RSCOE Pune, India. Author is passionate about design analysis and rendering of Automobile. Author is FEA Head at Team Redline Racing.

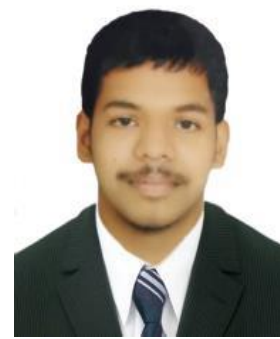

Omkar C. Taru

The Author is currently in the third year of bachelors of Mechanical Engineering from the JSPM'S RSCOE Pune, India. His interest include mechatronic works and Products Design. 